\title{
Brief review on recent outcomes of applications of green synthesis vs chemical synthesis of silver nanoparticles
}

\author{
Kirti Rani \\ Assistant Professor, Amity Institute of Biotechnology, Amity University Uttar Pradesh, Noida, Uttar Pradesh, India
}

Corresponding Author: Kirti Rani

Email: krsharma@amity.edu

\begin{abstract}
Silver nanoparticles (AgNP) have been already proposed for many advanced research approaches in the fields of therapeutics and nanomedicine due to their non-antigenicity and more potent optical characteristics along with their respective antioxidant and antimicrobial properties in effective site specific targeted drug-delivery practices systems. In last few years, chemically synthesized metal based nanoparticles has been studies for their biological and delivery behaviours because of use of various chemical and bio-hazardous chemicals in their preparations. Various previous studies on green synthesis of silver metal based nanoparticles have been designed which involved biological sources like microorganisms, plants and herbal extracts as cost effective, eco-friendly and non-toxic approaches. So that, green synthesis of silver nanoparticles has been much exploited in wider range of applications in the field of biomedical, therapeutics, nanomedicine and pharmaceuticals as more potent and safe drug delivery vehicles as compared to chemically preparations of silver nanoparticles. Therefore, in this review, we recollected the comparative studies based on advantages of green approaches of silver nanoparticles over their respective chemical preparations.
\end{abstract}

Keywords: Silver nanoparticles, Green synthesis, Therapeutics, Nanomedicine, Drug delivery vehicles.

\section{Introduction}

These days, bionanotechnology and nanomedicine are considered major thrust areas for clinical and pharmaceutical application because of using various metals or metal based conjugates which in turn, have excellent optical, chemical and biological properties. ${ }^{1}$ Nanoparticles synthesised in the range of $100 \mathrm{~nm}$ have been considered most as drug-delivery agents in various therapeutical, nanodiagnostics, cosmetological, biomedical and pharmaceutical approaches as well as also considered in chemical industriesa and waste water treatment facilities. ${ }^{2}$ Moreover, in the past few decades, silver nanoparticles also proposed for preparation of more sensitive and advanced biosensors. $^{3}$

The green synthesis of metal based nanoparticles were carried out by using biotic entities like microorganisms, plants, algae and fungi. ${ }^{4}$ Nanoparticles prepared from herbal and fungal sources are found to more biocompatible with the living system due to presence of bioactive groups when compared with chemically synthesised nanoparticles. ${ }^{5-7}$

Recently, more advanced green approach have been considered for preparing silver nanoparticle as biological reducing, free radical scavenging and capping agents which found to reduce $\mathrm{Ag}^{+}$to $\mathrm{Ag}^{0}{ }^{8}$ Hence, a broad range of various biological agents are considered for rapid, safe and green synthesis of silver nanoparticles by using bacteria, fungi/plant extracts, yeast and secondary metabolites. ${ }^{9,10}$ Cost effective standardization of silver nanoparticle size were found to achieve by using fungal agents in the range of $20-80 \mathrm{~nm} .^{11-13}$

Chemically synthesised silver nanoparticles are found to affect membrane permeability that result in the formation of harmful ROS (reactive oxygen species) and cause inflammation in the cells. On the contrary, biologically synthesised silver nanoparticles are biocompatible with the living system and do not illicit any fatal immune response due to the presence of bioactive group acting as reducers and capping agents. ${ }^{14}$ Since these silver nanoparticles are majorly used in sunscreen lotions, ointments, toothpastes and cosmetic products as compared to chemically synthesized silver nanoparticles. ${ }^{15}$ Green synthesis of silver nanoparticles via plant extracts or microorganisms is rapid and quick. Secondary metabolites from various biological agents act as reducers and stabilisers thus reducing our dependency on toxic chemicals for preparing silver nanoparticles when their applications are to be subjected in clinical and pharmaceutical studies. ${ }^{16}$

\section{Green synthesis of silver nanoparticles}

\section{Green Synthesis by using Plants and Phytochemicals}

In the past few years, many reports have carried out which were based on use of algal plants, gymnosperms and angiosperms to prepare silver nanoparticles. A marine brown algae was used to prepare silver nanoparticle in the range of $0.5-50 \mathrm{~nm}$ exhibiting shapes of spherical and polygonal as well as observed for their respective antimicrobial properties [17-20]. Silver nanoparticles prepared from extract of roots of Delphinium denudatum have been studied for their respective antibacterial and larvicidal activity against mosquito larvae..$^{21}$ A recent study have been also proposed for green synthesis of silver nanoparticles by using a medicinal plant Momordica charantia which further subjected for targeted infections caused by earthworms ( $P$. posthuma) and mosquito larvae A. albopictus and A. aegypti. ${ }^{22}$ Another study also carried out for the preparation of antibacterial and anticancer anisotropic silver nanoparticles by using leaf extract of Dodonaea viscosa. ${ }^{23}$ Many other plants like Azadirachta indica (Neem), Tinospora cordifolia (Giloy) and Catharanthus roseus (periwinkle) have been widely used as 
biological agents for green preparation of silver nanoparticle. ${ }^{24}$ Phytochemicals like nimbin, salannin, phenols, triterpenoids, amino acids have also been also proposed as capping agents for rapid and biodegradable silver based nanoparticle synthesis by involving more advanced techniques like electro-sonication. ${ }^{25-28}$

\section{Green synthesis by using Bacteria}

In many reports, bacteria are considered a safe, environment friendly and non-toxic bio-agents to produce silver based nanoparticles in which lesser amount of toxic by-products were found to reported by minimizing the cost of chosen downstream processing methods because Bacteria are highly resistant to extreme environmental conditions like extreme $\mathrm{pH}$, temperature, salinity and pressure. ${ }^{29-31}$ Silver nanoparticle preparations by using bacteria called Pseudomonas stutzeri and Morganella sp were reported whose particles size observed in the range of 5-20nm and chosen bacterial species produce silver nanoparticles intracellularly and extracellulary respectively. ${ }^{31}$ In another study, Lactobacillus strains present in dairy products like buttermilk produced crystalline silver nanoparticles when exposed to extracellular $\mathrm{Ag}^{+}$ions in growth media. ${ }^{32,33}$ Intracellularly, anionic groups like carboxyl groups attached to bacterial cell walls and their organelles are attracted by $\mathrm{Ag}^{+}$ions which undergo bio-reduction by intracellular proteins and co-enzymes to produce silver nanoparticles which reduces its purification processes and in turn reduces the labour cost. ${ }^{33}$

\section{Green synthesis by using Fungi}

Fungal species have been widely used for synthesis of silver nanoparticles in the range of $4-90 \mathrm{~nm}$ because of their ability to secrete large quantities of proteins, enzymes and extracellular secondary metabolites which results in rapid bio-reduction of dissolved silver salts resulted in extracellular synthesis. ${ }^{34,35}$ Fungal based green synthesis of silver nanoparticles also have higher metal and metalloid resistance and binding capacity as more potent antibacterial and anti-cancerous bio-agents when compared to bacterial green synthesis. ${ }^{35}$ In a recent study, a known fungal species, Botryodiplodia theobromae was exploited for silver nanoparticles when exposed to silver-salt solution which observed to have ideal cytotoxic activity against breast and lung cancer cell lines. ${ }^{36}$ Mycosynthesis of silver nanoparticles was proposed from Fusarium solani, a phytopathogen attacking onion, when exposed to a $1 \mathrm{mM}$ $\mathrm{AgNO}_{3}$ solution. ${ }^{37}$ Contrary to bacterial synthesis, reports have also suggested that silver nanoparticles are formed on the surface of the mycelia in mycosynthesis. ${ }^{39,40}$ In a recent study, mycosynthesized silver nanoparticles from Penicillium oxalicum were also studied for its use as substituents for conventional antibiotics against strains of Staphylococcus and Salmonella. ${ }^{40}$ In another study, mycosilver nanoparticles from Solanum nigrum showed antifungal activity against plant fungal pathogens like Fusarium graminearum, Fusarium udum, Rhizoctonia solani and Aspergillus niger. ${ }^{41}$ Hence, scaling up of extracellular mycosynthesis of silver nanoparticles is found to be easier and cost-effective due to ease in handling of fungal cultures which reduces their respective labour and downstream processing costs are reduced due to extracellular production.

\section{Chemical synthesis of silver nanoparticles}

Chemical synthesis of silver nanoparticle synthesis is the most conventional and commonly followed approach by all the leading chemical and pharmaceutical industries in which colloidal dispersions of sliver solution is subjected in aqueous or organic solutions. ${ }^{42,43}$ But later, this methodology is found to be highly hazardous and costly due to usage of toxic chemical stabilisers, reducers, capping agents and solvents over the green approach of silver nanoparticles preparation by the scientific community when considered for clinical, biomedical, therapeutics, diagnostic, pharmaceutical and cosmetic applications. ${ }^{43-45}$ Chemical reduction is the most common chemical method of silver nanoparticle synthesis in which reduction of metal salts is carried out by organic and inorganic reducing agents like sodium citrate, ascorbate, N, N-dimethylformamide, toluene and sodium polyacrylate are used to reduce $\mathrm{Ag}^{+}$to $\mathrm{Ag}^{0}$ to prevent agglomeration and stabilization. ${ }^{44-46}$ Among other reported chemical methods, microemulsion techniques were also involved for silver nanoparticles preparation by using two immiscible organic phases for separation of metal saltreducer complex which stabilised by alkyl groups which required huge amount of chemicals. ${ }^{45}$ So, green synthesis does not require huge amount of costly chemicals for stabilization and capping process as compared to chemically synthesized silver nanoparticles which require large amount of costly toxic chemicals. Green synthesis medicated silver nanoparticles are found to have considerable better optical stability as compared to chemically synthesized nanoparticles. ${ }^{46}$ In a recent study, silver nanoparticles were prepared by electrolysis of pure silver-acetate solution and nanoparticles were dispersed in ethylene glycol solution. ${ }^{47}$ And it was also synthesised from electrolysis of silver electrode in presence of a catalytic solution of hydrazine and formaldehyde. $^{48}$

\section{Recent applications of green synthesis mediated silver nanoparticles}

The green synthesis of silver nanoparticles has gained wide popularity due to non-toxic approach, its cost-effectiveness, environment friendly properties, biocompatibility, rapid synthesis and antibacterial/anti-parasitic characteristics when compared to chemically synthesized silver nanoparticles. So, Green synthesized nanoparticles have highly preferable for biomedical industry, human health care, textiles, bioremediation and automotive industry over chemically synthesized silver nanoparticles. In recent years, biologically synthesised silver nanoparticles have been proposed for biomedical applications like bio-labelling, magnetic separations, MRI contrast agents, implants and their use in accelerated wound healing. ${ }^{49}$ A recent study has depicted that faster wound healing activity was achieved by 
using silver nanoparticles synthesised from seaweed Caulerpa scalpelliformis. ${ }^{50}$ These silver nanoparticles also found to have anti-angiogenic and anti-proliferative properties. Anti-proliferative activity was observed from silver nanoparticles obtained from Derris trifoliate against lung cancer cell line A549. ${ }^{51}$ Imaging application of these silver nanoparticles are also used for wide fluorescence imagining, surface enhanced raman spectroscopy to colorimetric imaging which a unique extinction spectra. ${ }^{52}$ Air disinfection and purification can also be enabled by the usage of these green silver nanoparticles. Development of silver nanoparticle based air filters has used for reduction of biological and particulate matter air contamination. ${ }^{53}$ Nanoparticles synthesised from medicinal plants are found to have excellent with antimicrobial properties which increase the antimicrobial potential of silver as compared to chemically synthesized nanoparticles. ${ }^{54-57}$ In a recent study, catalytic degradation of reactive dyes was carried out by using silver nanoparticles which were synthesised from Eriobotrya japonica. ${ }^{58}$ In another study, photocatalytic degradation of Methyl Orange and Methylene Blue were also carried out by silver nanoparticles synthesised from flower extract of Passiflora edulis which confirmed by spectrophotometric analysis. ${ }^{59}$

\section{Conclusions}

This review is based on the most advanced and recent investigations of green and chemical preparation of sliver nanoparticles. So, brief informations of this review may helpful to recollect the highlights on advantages of green synthesis of silver nanoparticles to be used as safer, nontoxic, cost-effective, biocompatible and eco-friendly approach over most conventional chemical synthesis of prepare silver nanoparticles. Bacteria, fungi and medicinal plants and other herbal plants species are found to be cheaper sources as well as more potent, biodegradable, antimicrobial and anti-pathogenic agents to prepare silver nanoparticles as compared to chemically synthesized nanoparticles. Green synthesis also found to be economic viable over chemical methods due to minimal use of any hazardous chemicals, costly solvents, involvement of lowcost downstream processing techniques and low labour cost. Hence, green approaches used to prepare silver metal based nanoparticles can be more safe approach as compared to chemically synthesized silver nanoparticles in various applications in cosmetics, therapeutics, biomedical applications, clinical, pharmaceutical, air disinfection process, fumigation, bioremediation and biocatalysis.

\section{Acknowledgment}

I would like also to express my cordially appreciation to Amity University Uttar Pradesh, Noida (India).

\section{Source of funding}

None.

\section{Conflict of interest}

None.

\section{References}

1. Lee S.H, \& Jun B.H. Silver Nanoparticles: Synthesis and application for nanomedicine. Int J Mol Sci 2019;20(4):865.

2. Iravani S, Korbekandi H, Mirmohammadi S.V, \& Zolfaghari B. Synthesis of silver nanoparticles: chemical, physical and biological methods. Res Pharm Sci 2014;9(6), 385.

3. Mukherji S, Bharti S, Shukla G, \& Mukherji S. Synthesis and characterization of size-and shape-controlled silver nanoparticles. Physical Sci Rev 2019;4(1).

4. Kotcherlakota R, Das S, \& Patra C.R. (2019). Therapeutic applications of green-synthesized silver nanoparticles. In Green Synthesis, Characterization and Applications of Nanoparticles 2019;389-428. Elsevier.

5. Sharma V, Kaushik S, Pandit P, Dhull D, Yadav J.P, \& Kaushik S. Green synthesis of silver nanoparticles from medicinal plants and evaluation of their antiviral potential against chikungunya virus. Applied microbiology and biotechnology, 2019;103(2):881-91.

6. de Souza T.A.J, Souza L.R.R, \& Franchi L.P. Silver nanoparticles: An integrated view of green synthesis methods, transformation in the environment, and toxicity. Ecotoxicol Environ saf 2019;171:691-700.

7. Aritonang H.F, Koleangan H, \& Wuntu A.D. (2019). Synthesis of Silver Nanoparticles Using Aqueous Extract of Medicinal Plants (Impatiens balsamina and Lantana camara) Fresh Leaves and Analysis of Antimicrobial Activity. Int J Microbiol 2019.

8. Zuorro A, Iannone A, Natali S, \& Lavecchia R.Green Synthesis of Silver Nanoparticles Using Bilberry and Red Currant Waste Extracts. Processes 2019;7(4), 193.

9. Yadav S.G, Patil S.H, Patel P, Nair V, Khan S, Kakkar, S, \& Gupta A.D. Green synthesis of silver nanoparticles from plant sources and evaluation of their antimicrobial activity. In $A d v$. Anal. Tools Mater Charact 2018;5:133-9.

10. Upadhyay P, Mishra S.K, Purohit S, Dubey G.P, Singh Chauhan B, \& Srikrishna S et al. Antioxidant, antimicrobial and cytotoxic potential of silver nanoparticles synthesized using flavonoid rich alcoholic leaves extract of Reinwardtia indica. Drug Chem Toxicol 2019;42(1):65-75.

11. Vardhana J, \& Kathiravan G. (2015). Biosynthesis of silver nanoparticles by endophytic fungi Pestaloptiopsis pauciseta isolated from the leaves of Psidium guajava Linn. Int J Pharm Sci Rev Res 2015;31(1):29-31.

12. Zomorodian K, Pourshahid S, Sadatsharifi A, Mehryar P, Pakshir K, Rahimi M.J et al, (2016). Biosynthesis and characterization of silver nanoparticles by Aspergillus species. Bio Med Res Int 2016.

13. Gour A, \& Jain N.K. Advances in green synthesis of nanoparticles. Artific Cells Nanomedicine, Biotechnol 2019;47(1):844-51.

14. Akther T, \& Hemalatha S. Mycosilver Nanoparticles: Synthesis, Characterization and its Efficacy against Plant Pathogenic Fungi. BioNanoScience, 2019;9(2):296-301.

15. Agrawal S, Bhatt M, Rai S.K, Bhatt A, Dangwal P, \& Agrawal P.K et al. (2018). Silver nanoparticles and its potential applications: A review. J Pharm Phytochem 2018;7:930-7.

16. Dragan C.I, Pantilimon C, Popa E.E, Coman G, \& Gradinaru C. Green Synthesis, Characterization and Antimicrobial of Silver Nanoparticles. Univ Politehnica Buchar Sci Bull Ser BChemistry Mater Sci 2018;80(4):267-75.

17. Abdel-Raouf N, Al-Enazi NM, Ibraheem I.B.M, Alharbi R.M, \& Alkhulaifi M.M. Biosynthesis of silver nanoparticles by using of the marine brown alga Padina pavonia and their characterization. Saudi J Biol Sci 2019;26(6):1207-15.

18. Arya G, Kumari R.M, Sharma N, Gupta N, Kumar A, Chatterjee $\mathrm{S}$ et al, Catalytic, antibacterial and antibiofilm efficacy of biosynthesised silver nanoparticles using Prosopis 
juliflora leaf extract along with their wound healing potential. J Photochem Photobiol B: Biol 2019;190:50-8.

19. Abdelghany T.M, Al-Rajhi A.M, Al Abboud M.A, Alawlaqi M.M, Magdah A.G., Helmy E.A et al., Recent advances in green synthesis of silver nanoparticles and their applications: About future directions. A review. Bio Nano Sci 2018;8(1):516.

20. Veisi H, Azizi S, \& Mohammadi P. Green synthesis of the silver nanoparticles mediated by Thymbra spicata extract and its application as a heterogeneous and recyclable nanocatalyst for catalytic reduction of a variety of dyes in water. J Cleaner Prod 2018;170:1536-43.

21. Suresh G, Gunasekar P.H, Kokila D, Prabhu D, Dinesh D, Ravichandran N, Siva G. V et al. Green synthesis of silver nanoparticles using Delphinium denudatum root extract exhibits antibacterial and mosquito larvicidal activities. Spectrochimica Acta Part A: Molecul Biomol Spectroscopy 2019;127;61-6.

22. Shelar A, Sangshetti J, Chakraborti S, Singh A.V, Patil R, \& Gosavi $\mathrm{S}$ et al. Helminthicidal and Larvicidal Potentials of Biogenic Silver Nanoparticles Synthesized from Medicinal Plant Momordica charantia. Med Chem 2019;15(7):781-9.

23. Anandan M, Poorani G, Boomi P, Varunkumar K, Anand K, Chuturgoon A.A et al, Green synthesis of anisotropic silver nanoparticles from the aqueous leaf extract of Dodonaea viscosa with their antibacterial and anticancer activities. Process Biochem 2019;80:80-8.

24. Srikar S.K, Giri D.D, Pal D.B, Mishra P.K, \& Upadhyay S.N. Green synthesis of silver nanoparticles: a review. Green Sustainable Chem 2016;6(01):34.

25. Elumalai E.K, Kayalvizhi K, \& Silvan S. Coconut water assisted green synthesis of silver nanoparticles. J Pharm Bioallied Sci 2014;6(4):241.

26. Nadagouda M.N, Iyanna N, Lalley J, Han C, Dionysiou D.D, \& Varma R.S et al. Synthesis of silver and gold nanoparticles using antioxidants from blackberry, blueberry, pomegranate, and turmeric extracts. ACS Sustainable Chem Eng 2014;2(7):1717-23.

27. El-Sherbiny I.M, \& Sedki M. Green Synthesis of ChitosanSilver/Gold Hybrid Nanoparticles for Biomedical Applications. Pharm Nanotechnol 2019;79-84. Humana, New York, NY.

28. Ramanathan A.A, \& Aqra M.W. An overview of the Green Road to the Synthesis of Nanoparticles. J Mater Sci Res Rev 2019;1-11.

29. Fang X, Wang Y, Wang Z, Jiang Z, \& Dong M. Microorganism assisted synthesized nanoparticles for catalytic applications. Energies, 2019;12(1):190.

30. Ulug B, Turkdemir M.H, Cicek A, \& Mete A. Role of irradiation in the green synthesis of silver nanoparticles mediated by fig (Ficus carica) leaf extract. Spectrochimica Acta Part A: Molecular and Biomolecular Spectroscopy, 2015;135:153-61.

31. Reverberi A, Vocciante M, Lunghi E, Pietrelli L, \& Fabiano B. (2017). New trends in the synthesis of nanoparticles by green methods. Chem Eng Trans 2017;61:667-72.

32. Anandaradje A, Meyappan V, Kumar I, \& Sakthivel N. Microbial Synthesis of Silver Nanoparticles and Their Biological Potential. Nanoparticles Med 2020;99-133. Springer, Singapore.

33. Aziz S.M, Mirhosseini S.A, Rastegar M.S.P, \& Mahmoodzadeh H.H. Characterization of Biosynthesized Silver Nanoparticles Using Lactobacillus rhamnosus GG and its In Vitro Assessment Against Colorectal Cancer Cells. Probiotics and antimicrobial proteins. 2019.

34. Siddiqi K.S, Husen A, \& Rao R.A. A review on biosynthesis of silver nanoparticles and their biocidal properties. $J$ Nanobiotechnology 2018;16(1):14.
35. Shanmuganathan R, Karuppusamy I, Saravanan M, Muthukumar H, Ponnuchamy K, Ramkumar V.S, \& Pugazhendhi A et al. Synthesis of Silver nanoparticles and their biomedical applications-A comprehensive review. Current pharmaceutical design, 2019;25(24):2650-60.

36. Ahmad S, Munir S, Zeb N, Ullah A, Khan B, Ali J et al, Green nanotechnology: a review on green synthesis of silver nanoparticles-an ecofriendly approach. Int $J$ Nanomed 2019;14:5087.

37. Janakiraman V, Govindarajan K, \& Magesh C.R. Biosynthesis of Silver Nanoparticles from Endophytic Fungi, and its Cytotoxic Activity. Bio NanoScience, 2019;1-7.

38. Ingle A, Rai M, Gade A, \& Bawaskar M. Fusarium solani: a novel biological agent for the extracellular synthesis of silver nanoparticles. J Nanoparticle Res 2009;11(8):2079.

39. Khan N.T, Khan M.J, Jameel J, Jameel N, \& Rheman S.U.A. An Overview: Biological organisms that serves as nanofactories for metallic nanoparticles synthesis and fungi being the most appropriate. Bioceram Dev Appl, 2017;7(101):2.

40. Guilger-Casagrande M, \& de Lima R. Fungal mediated synthesis of silver nanoparticles: A review. Frontiers Bioengineering Biotechnol 2019;7:287.

41. Akther T, \& Hemalatha S. Mycosilver Nanoparticles: Synthesis, Characterization and its Efficacy against Plant Pathogenic Fungi. Bio Nano Sci 2019;9(2):296-301.

42. Zhang W, Xiao B, \& Fang T. Chemical transformation of silver nanoparticles in aquatic environments: Mechanism, morphology and toxicity. Chemosphere 2018;191:324-34.

43. Starnes D.L, Lichtenberg S.S, Unrine J.M, Starnes C.P, Oostveen E.K, Lowry G.V et al. Distinct transcriptomic responses of Caenorhabditis elegans to pristine and sulfidized silver nanoparticles. Environ Pollut 2016;213:314-21.

44. Deng J.P, Li S.H, Chang S.T, \& Shih Y.C. Hyaluronanassisted synthesis of silver nanoparticles and nanowires. Res Chem Intermediates 2019;45(1):119-25.

45. Kuntyi O.I, Kytsya A.R, Mertsalo I.P, Mazur A.S, Zozula G.I, Bazylyak L.I et al. Electrochemical synthesis of silver nanoparticles by reversible current in solutions of sodium polyacrylate. Colloid and Polymer Science, 2019;297(5):68995.

46. Mehdi M, Akhtar M, Abro S, Qamar Z, Nauman M. M, Aziz S et al. Electrochemical synthesis of AgNP and mechanical performance of AgNP-EG coatings on soft elastomer. $J$ Elastomers Plast 2019;0095244319879973.

47. Purushothaman B, Kulsi G, \& Song J.M. Preparation of highvalence bifunctional silver nanoparticles for wound-healing applications. In Design of Nanostructures for Versatile Therapeutic Applications 2018;451-486). William Andrew Publishing.

48. Malik M.A, Wani M.Y, \& Hashim M.A. Microemulsion method: A novel route to synthesize organic and inorganic nanomaterials: 1st Nano Update. Arabian J Chem 20125(4):397-417.

49. Tang S, \& Zheng J. Antibacterial activity of silver nanoparticles: structural effects. Adv Healthc Mater 2018;7(13):1701503.

50. Bansal V, Li V, O'Mullane A.P, \& Bhargava S.K. Shape dependent electrocatalytic behaviour of silver nanoparticles. Cryst Eng Comm 200;12(12):4280-6.

51. Manikandan R, Anjali R, Beulaja M, Prabhu N.M, Koodalingam A, Saiprasad G et al, Synthesis, characterization, anti-proliferative and wound healing activities of silver nanoparticles synthesized from Caulerpa scalpelliformis. Process Biochem 2019;79:135-41.

52. Cyril N, George J.B, Joseph L, Raghavamenon A.C., \& Sylas V.P. Assessment of antioxidant, antibacterial and antiproliferative (lung cancer cell line A549) activities of green 
synthesized silver nanoparticles from Derris trifoliata. Toxicology Res 2019;8(2):297-308.

53. Kelly K.L, Jensen T.R, Lazarides A.A, \& Schatz G.C. Modeling metal nanoparticle optical properties. Metal Nanoparticles: Synthesis, Characterization, and Appl 2002;89118.

54. Narang J, Rani K, Sonia I. \& Chaitali S. Green versus chemical synthesis of gold and silver nanoparticles. J Bionanosci 2016;10(5):341-7.

55. Barkat M.A, Harshita F.N, Beg S, Pottoo F.H, Garg A, Singh S.P et al, Silver Nanoparticles and their Antimicrobial Applications. Current Nanomedicine (Formerly: Recent Patents on Nanomedicine, 2018;8(3), 215-224.

56. Rani K \& Nandini Terway. Green synthesis of silver nitrate treated emulsified Elettaria cardamomum herbal suspensions and study their comparative antioxidant properties. Adv Tissue Eng Regen Med 2019;3(5):98-101.
57. Li A.Y, Gellé A, Segalla A, \& Moores A. Silver Nanoparticles in Organic Transformations. Silver Catalysis in Organic Synthesis, 2019;723-793.

58. Yu C, Tang J, Liu X, Ren X, Zhen M, \& Wang L. Green biosynthesis of silver nanoparticles using Eriobotrya japonica (thunb.) leaf extract for reductive catalysis. Mater 2019;12(1):189.

59. Thomas B, Vithiya B, Prasad T, Mohamed S.B, Magdalane C.M, Kaviyarasu K et al, Antioxidant and photocatalytic activity of aqueous leaf extract mediated green synthesis of silver nanoparticles using passiflora edulis f. flavicarpa. $J$ Nanosci Nanotechnol 2019;19(5):2640-48.

How to cite: Rani K. Brief review on recent outcomes of applications of green synthesis vs chemical synthesis of silver nanoparticles. IP Int $J$ Comprehensive Adv Pharmacol 2020;5(1):9-13. 